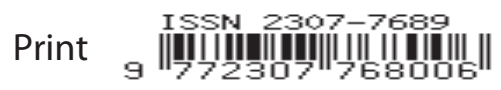

Mediscope

REVIEW ARTICLE

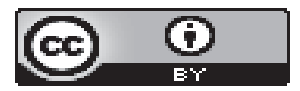

Online

IS: $2616-6054$

\title{
Extra Hepatic Portal Venous Obstruction in Children: Approach and Management
}

\author{
M Khadga1, M Benzamin², ASMB Karim³
}

\begin{abstract}
Portal hypertension in children is not uncommon and extra hepatic portal venous obstruction (EHPVO) constitute about $75 \%$ of portal hypertension. Several risk factors predispose to development of EHPVO such as neonatal sepsis, umbilical catheterization, severe dehydration, abdominal trauma or surgery etc. Common presentations are haematemesis and splenomegaly. Acute variceal bleeding is a medical emergency. Liver function is normal in extrahepatic portal hypertension unless there is portal bilopathy. High index of suspicion is the key of early diagnosis. Esophagogastrodudenoscopy is diagnostic for portal hypertension and doppler ultrasonography of portal vein confirm extra hepatic portal venous obstruction (EHPVO) in presence of thrombus and/or cavernoma. Adequate management including endotherapy, pharmacotherapy and/or surgery is an important key for better outcome.
\end{abstract}

Keywords: Extra hepatic portal venous obstruction, Children, Haematemesis, Splenomegaly.

\section{Definition:}

Portal hypertension (PHT) is a condition that occurs due to the formation of portalsystemic collaterals which shunt a portion of the portal blood flow to the systemic circulation, bypassing the liver. It can arise from disorders with blood flow at any level within the portal system. ${ }^{1}$ Extra hepatic portal venous obstruction (EHPVO) is an important cause of portal hypertension which constitutes $68-76 \%$ of portal hypertension in children from developing countries. The relation of haematemesis, splenomegaly and portal hypertension was first recognized by Banti almost a century ago. Majority of cases are due to primary thrombosis of the portal vein. ${ }^{2}$ Kobrich coined the term cavernoma to describe spongy appearance of portal vein (PV). ${ }^{3}$ As per the Asia Pacific association for study of Liver (APASL) consensus (2006), EHPVO is defined as "a vascular disorder of liver, characterized by obstruction of the extrahepatic PV with or without involvement of intrahepatic PV radicles or splenic or superior mesenteric veins". The recent Baveno VI consensus definition adds recent thrombus in the PV in the definition along with the presence of cavernoma, however, excludes cirrhosis and other liver condition like Idiopathic portal hypertension. ${ }^{5}$

1. Dr. Mukesh Khadga, Resident, Department of Pediatric Gastroenterology and Nutrition, Bangabandhu Sheikh Mujib Medical University (BSMMU), Dhaka, Bangladesh.

2. Dr. Md. Benzamin, Resident, Department of Pediatric Gastroenterology and Nutrition, Bangabandhu Sheikh Mujib Medical University (BSMMU), Dhaka, Bangladesh.

3. Dr. ASM Bazlul Karim, Chairman and professor, Department of Pediatric Gastroenterology and Nutrition, Bangabandhu Sheikh Mujib Medical University (BSMMU), Dhaka, Bangladesh. 
Incidence:

PVT is responsible for $5 \%-10 \%$ of all cases of portal hypertension in western countries. About $40 \%$ are attributed to PVT in developing countries. In children, EHPVO accounts for $80 \%$ cases of PHT. After cirrhosis (upto $64.1 \%$ ), EHPVO is the most common cause of portal hypertension globally. In the Indian subcontinent, $20 \%-30 \%$ of all variceal bleeds are due to EHPVO.6,7

\section{Etiology:}

The etiology of EHPVO is diverse and risk factors are usually detected in less than half of patients. Common local causes are: omphalitis, portal vein phlebitis, umbilical vein catheterization (UVC), pancreatitis, liver abscess, surgery around portal vein (splenectomy, cholecystectomy, Billroth-II procedure), and malignancies (pancreatic, hepatic, or duodenal).8-10 Systemic causes include diarrheal illnesses, abdominal sepsis, and nephrotic syndrome.11,12 A combination of local and systemic factors is seen in $19-64 \%$ of patients. ${ }^{10}$

Congenital anomalies have been reported in $30 \%$ of children with EHPVO-more often in those without history of omphalitis-the commonest ones were cardiovascular and urinary tract abnormalities, others had Turner's syndrome, cleft lip and palate, coloboma, external ear, and limb deformities. ${ }^{11,13}$ Finally, idiopathic cases constitute around $13-28 \%$ of adults and $26-62 \%$ of children with EHPVO. 8

\section{Pathophysiology:}

According to the unifying hypothesis, a major thrombotic event occurring at a young age involves main PV resulting in EHPVO, whereas repeated microthrombotic events later in life involve small or medium branches of PV leading to Idiopathic portal hypertension (IPH). Dual theory explains development of IPH secondary to increased splenic blood flow secondary to high inducible nitric oxide synthase (iNOS) and intrahepatic obstruction.8 Endothelial-mesenchymal transition (EndMT) theory says that vascular endothelial cells of portal venules acquire myofibroblastic features leading to collagen synthesis and subsequent occlusion of small PV branches. ${ }^{14}$ Pathologically, there is cavernomatous transformation of the PV $\square$ a cluster of varying sized vessels replacing $P V$ that are arranged haphazardly within connective tissue support at the liver hilum. These collaterals may extend for a variable length inside and outside the liver. Architectural pattern of liver is well preserved. Mild periportal fibrosis may be seen. 8,15

\section{Clinical presentation:}

EHPVO has a bimodal age of presentationthose secondary to UVC, omphalitis, or perinatal events usually manifest early (within 3 years), whereas those following intraabdominal infections or idiopathic ones manifest late (8 years) or sometimes into early adulthood.8 Variceal bleed (49-85\%) and splenomegaly (63-88\%) are the commonest presentations in children. Mean ages of first bleeding episode are around 3.8-5.2 years.16-24 In developing country, the diagnosis is mostly delayed up to a mean age of 6.3-9.3 years till the children have a mean number of 1.8-3.1 bleeding episodes before presentation.16, 25,26 Ascites is present in $4 \%$ of children and is often transient, related to the bleeding episode, growth failure, and hypoalbuminemia. ${ }^{19,27}$

\section{Investigations:}

Liver function test (LFT): Usually normal. Elevations of alkaline phosphatase and gamma-glutamyl transpeptidase are seen with development of portal biliopathy, while hypoalbuminemia may be seen during bleed episodes particularly in the setting of growth failure. 8,15

Endoscopy: Esophageal varices (fig 1), gastric varices, anorectal varices. It is seen that EHPVO children have greater proportion of high risk varices than the cirrhotic etiologies (70 vs $32 \%$ ), esophageal varices are seen in $85-94 \%$ and two-thirds have large varices with red colour signs. 28 Doppler ultrasonography of portal vein: PV thrombosis and 
portal vein cavernoma (sensitivity and specificity of >95\%).8,15 Contrast-enhanced CT and CT angiogram: Cavernomatous transformation of portal vein with splenomegaly, collaterals, and/or no opacification of intrahepatic portal vein in chronic EHPVO.29 MRCP for portal biliopathy (fig 4).29 Liver biopsy: Normal but not mandatory. ${ }^{29}$

\section{Management:}

Control and prophylaxis of variceal bleed:

Treatment option includes vasoconstrictor drugs (octreotide), endotherapy- endoscopic sclerotherapy and endoscopic variceal ligation and propranolol. Octreotide used to control active variceal bleeding, 1-2 micro $\mathrm{gm} / \mathrm{kg}$ stat at bolus dose followed by $1-2$ micro $\mathrm{gm} / \mathrm{kg} /$ hour at maintenance dose for 3-5 days. Band ligation followed by sclerotherapy may be a better alternative to sclerotherapy alone in children and used for both control of active variceal bleeding and prophylaxis. Endoscopic sclerotherapy (EST) (fig. 2) and endoscopic variceal ligation (EVL) (fig. 3) both are highly effective in controlling acute variceal bleeding in over $90 \%$ of cases along with eradication of variceal bleeding. Propranolol given for primary and secondary prophylaxis of variceal bleeding at a dose of $1-5 \mathrm{mg} / \mathrm{kg} /$ day to achieve $25 \%$ reduction in pulse rate. Propranolol must be withheld during bleeding episode. ${ }^{11,19,30}$

\section{Role of surgery:}

Meso-Rex shunt or Mesenterico-left portal vein bypass (MLPVB), decompresses superior mesenteric vein into left branch of $P V$ (LPV) via an autologous graft, is the surgical shunt of choice in EHPVO. It restores hepatic portal blood flow in the closest possible physiological manner, and in a long run protects liver from parenchymal extinction. ${ }^{31-33}$

\section{Role of radiological intervention:}

Transjugular intrahepatic portosystemic shunt (TIPSS) - feasible in a non-cirrhotic PVT. Indications are: PHT complications (recurrent bleed, refractory ascites) getting difficult to manage medically, or need of anticoagulation in the presence of large varices. ${ }^{34,35}$ Shunt reduction or closure is done by using coils or balloon occluded trans-venous obliteration. ${ }^{35}$

Role of anti-coagulation:

In EHPVO with prothrombotic state as a cause, anti-coagulant can be started taking into consideration the risk of bleeding from the varices. ${ }^{8}$

\section{Management of portal biliopathy:}

Endoscopic decompression is favoured for symptomatic PB (like jaundice, cholangitis, choledocholithiasis, or biliary stricture). However, in the long run, most of these patients require a shunt surgery. Biliary diversion procedures are rarely needed in case the symptoms of biliary obstruction persist after shunt. $8,36-38$

Portal vein thrombosis and liver transplant:

Portal vein thrombosis is seen in $2 \%-6 \%$ post-transplantat Patient. 39,40 Portal vein thrombosis in pre-transplant was considered as an absolute contraindication for liver transplantation. With the advancement in the treatment options, portal vein thrombosis can represent itself as an indication for liver transplant. ${ }^{41,42}$ The first successful liver transplant in patients with portal vein thrombosis was reported by Shaw. ${ }^{43}$

\section{Follow Up:}

Regular 6 monthly follow-up of all patients with EHPVO is mandatory to look for spleen size, growth, quality of life, school performance, development of jaundice, decompensation, portal biliopathy (PB), and hepato pulmonary syndrome, and to assess their laboratory values and imaging for PVT and PB. ${ }^{8}$

\section{Conclusion:}

EHPVO is a childhood disorder causing PHT, where the etiology is either perinatal or early childhood vascular insult. The diagnosis is relatively easy if a high index of suspicion is kept. The management is mostly endoscopic with a good long-term outcome. ${ }^{8}$ 


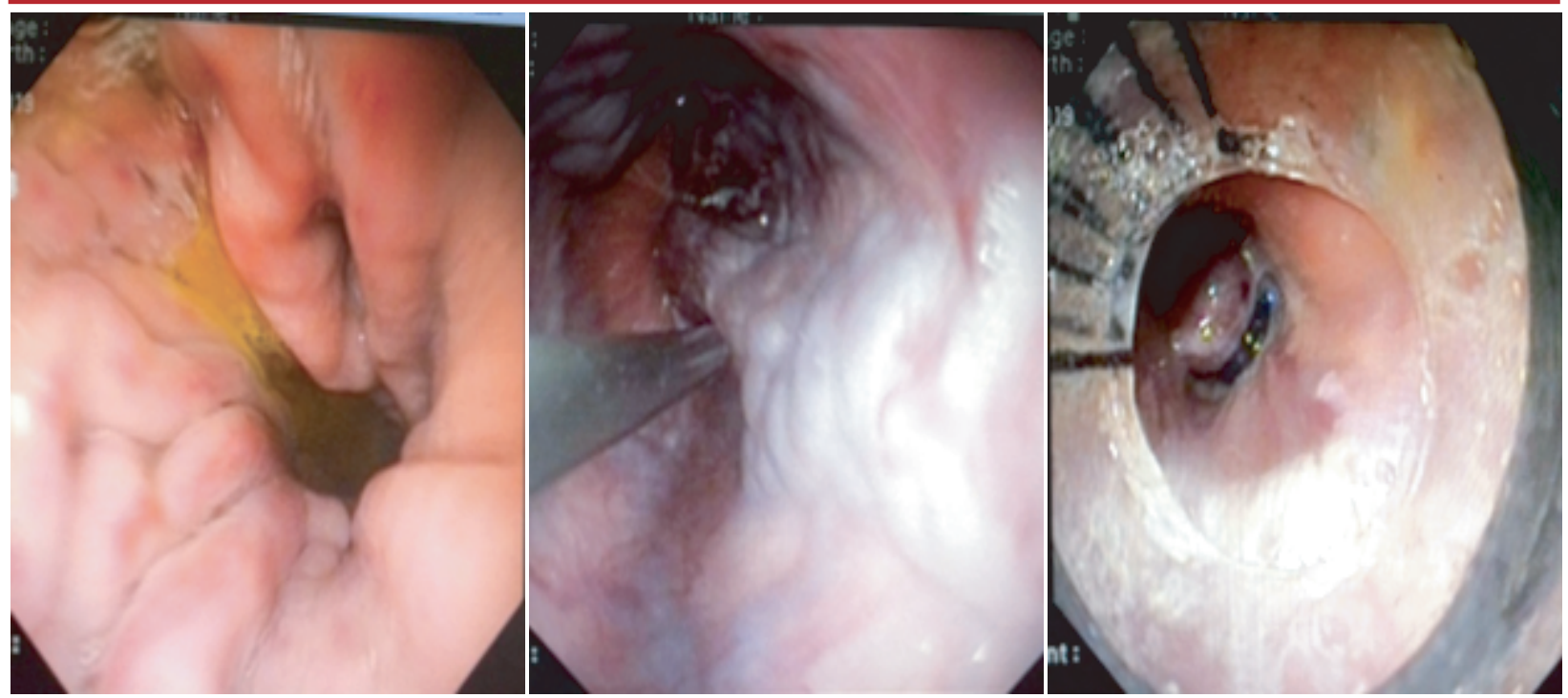

Figure 1: Grade III oesophageal varices on endoscopy
Figure 2: Enoscopic sclerotherapy in grade IV varices
Figure 3: Endoscopic variceal ligation

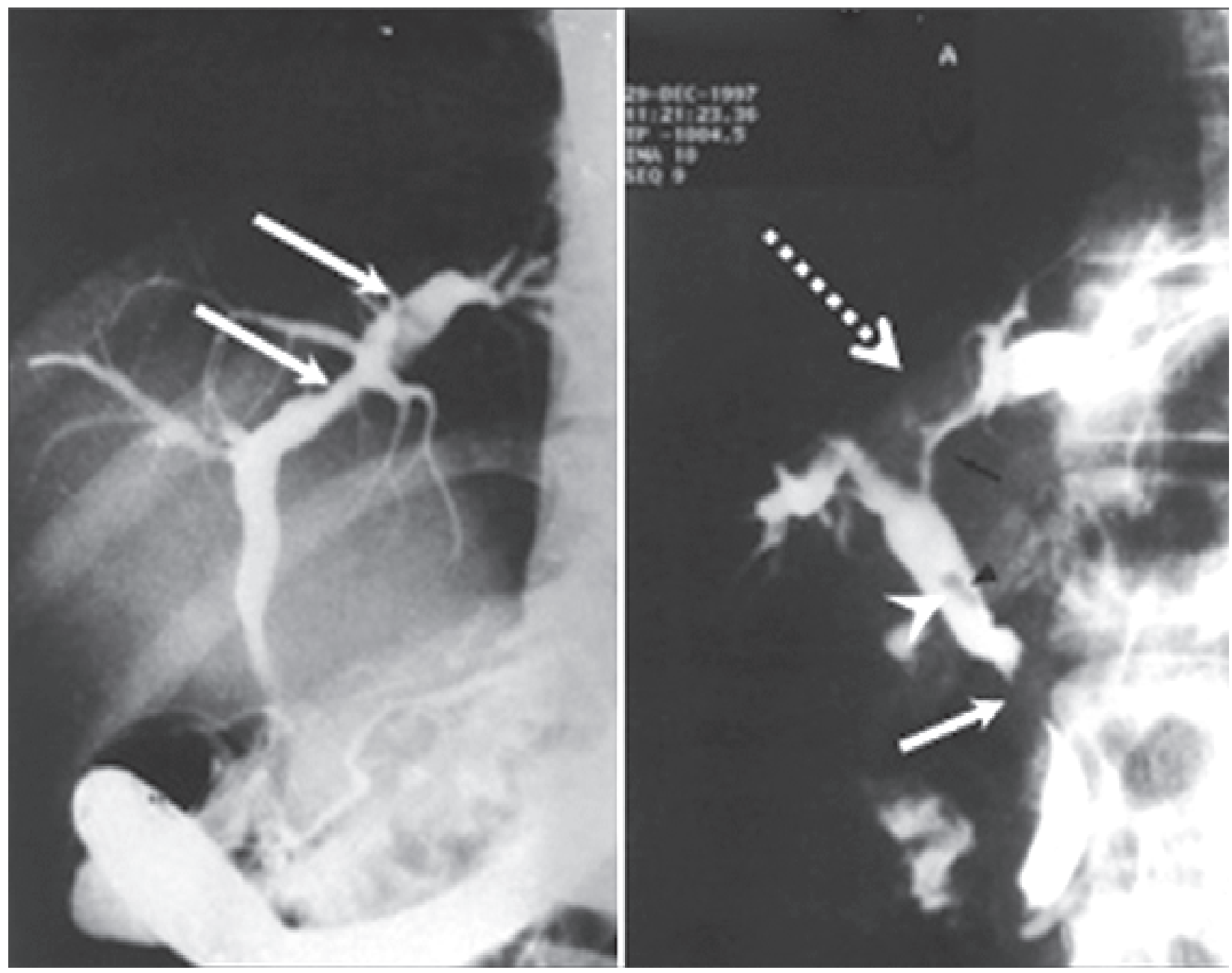

Figure 4: Cholangiogram revealing portal biliopathy in the form of indentations, irregularity of walls, strictures and dilatations, angulation, displacement, and stones. 29 


\section{References:}

1. Bosch J, Abraldes JG, Groszmann R. Current management of portal hypertension. J Hepatol. 2003;38 Suppl 1:S54-68.

2. Rajesh S.Shinde, Kishore Adyanthaya, Rajesh Yadav, Extrahepatic Portal Hypertension - Review of 40 Cases, Bombay Hospital Journal, , 2012 ;54:273-28.

3. Peter L, Dadhich SK, Yachha SK. Clinical and laboratory differentiation of cirrhosis and extrahepatic portal venous obstruction in children. J Gastroenterol Hepatol. 2003;18:185-189.

4. Sarin SK, Sollano JD, Chawla YK, Amarapurkar D, Hamid S, Hashizume M, et al. Members of the APASL working party on portal hypertension. Consensus on extra-hepatic portal vein obstruction. Liver Int 2006;26(5):512-519.

5. De Franchis R, Baveno VI Faculty. Expanding consensus in portal hypertension report of the Baveno VI consensus workshop: stratifying risk and individualizing care for portal hypertension. J Hepatol 2015;63:743-752.

6. Sarin SK, Kapoor D. Non-cirrhotic portal fibrosis: Current concepts and management. J Gastroenterol Hepatol. 2002;17:526-34.

7.Amitrano L, Guardascione1 MA, Brancaccio V, Margaglione M, Manguso F, lannaccone $\mathrm{L}$, et al. Risk factors and clinical presentation of portal vein thrombosis in patients with liver cirrhosis. J Hepatol. 2004;40:736-41.

8. Khanna R, Sarin SK. Non-cirrhotic portal hypertension. J Hepatol 2014;60:421441.

9. Janssen HL, Wijnhoud A, Haagsma EB, van Uum $\mathrm{SH}$, van Nieuwkerk $\mathrm{CM}$, Adang RP, Chamuleau RA, van Hattum J, Vleggaar FP, Hansen BE, Rosendaal FR, van Hoek B. Extrahepatic portal vein thrombosis: aetiology and determinants of survival. Gut 2001;49(5):720-724.

10. Sogaard KK, Astrup LB, Vilstrup H, Gronbaek $H$. Portal veinthrombosis; risk factors, clinical presentation and treatment.BMC Gastroenterol 2007;7:34
11. Abd El-Hamid N, Taylor RM, Marinello D, et al. Aetiology and management of extrahepatic portal vein obstruction in children: King's College Hospital experience. J Pediatr Gastroenterol Nutr 2008;47:630634

12. Weiss B, Shteyer E, Vivante A, et al. Etiology and long-term outcome of extrahepatic portal vein obstruction in children. World J Gastroenterol 2010;16:49684972.

13. Odie 'vre M, Pige' G, Alagille D. Congenital abnormalities associated with extrahepatic portal hypertension. Arch Dis Child 1977;52(5):383-385

14. Sato Y, Nakanuma Y. Role of endothelialmesenchymal transition in idiopathic portal hypertension. Histol Histopathol 2013;28(2):145-154.

15. Garcia-Pagan JC, Hernandez-Guerra M, Bosch J. Extrahepatic portal vein thrombosis. Semin Liver Dis 2008;28(3):282292.

16. Poddar U, Thapa BR, Rao KL, Singh K. Etiological spectrum of esphageal varices due to portal hypertension in Indian children: is it different from the West? J Gastroenterol Hepatol 2008;23:13541357.

17. El-Karaksy H, El-Koofy N, El-Hawary M, et al. Prevalence of factor $V$ Leiden mutation and other hereditary thrombophilic factors in Egyptian children with portal vein thrombosis: results of a single-center case-control study. Ann Hematol 2004;83:712-715.

18. El-Karaksy HM, El-Koofy N, Mohsen N, Helmy H, Nabil N, El- Shabrawi M. Extrahepatic portal vein obstruction in Egyptian children. J Pediatr Gastroenterol Nutr 2015;60(1):105-109

19. Giouleme O, Theocharidou E. Management of portal hypertension in children with portal vein thrombosis. J Pediatr Gastroenterol Nutr. 2013;57(4):419-425.

20. Pietrobattista A, Luciani M, Abraldes JG, Candusso M, Pancotti S, Soldati M, Monti L, Torre G, Nobili V. Extrahepatic portal vein thrombosis in children and adoles 
cents: Influence of genetic thrombophilic disorders. World J Gastroenterol 2010;16(48):6123-6127.

21. Weiss B, Shteyer E, Vivante A, et al. Etiology and long-term outcome of extrahepatic portal vein obstruction in children. World J Gastroenterol 2010;16:49684972.

22. Ferri PM, Rodrigues Ferreira A, Fagundes ED, Xavier SG, Dias Ribeiro D, et al. Evaluation of the presence of hereditary and acquired thrombophilias in brazilian children and adolescents with diagnoses of portal vein thrombosis. J Pediatr Gastroenterol Nutr 2012;55(5):599-604.

23. Shneider BL, de Ville de Goyet J, Leung DH, Srivastava A, Ling SC, Duche' M, et al. Primary prophylaxis of variceal bleeding in children and the role of Meso-Rex bypass: summary of the Baveno VI pediatric satellite symposium. Hepatology 2016;63(4):1368-1380

24. Alberti D, Colusso M, Cheli M, Ravelli P, Indriolo A, Signorelli S, Fagiuoli S, D'Antiga L. Results of a stepwise approach to extrahepatic portal vein obstruction in children. J Pediatr Gastroenterol Nutr 2013;57(5):619-626

25. Zargar SA, Yattoo GN, Javid G, Khan $B A$, Shah AH, Shah NA, et al. Fifteen-year follow up of endoscopic injection sclerotherapy in children with extrahepatic portal venous obstruction. J Gastroenterol Hepatol 2004;19:139-145

26. Thomas V, Jose T, Kumar S. Natural history of bleeding after esophageal variceal eradication in patients with extrahepatic portal venous obstruction: a 20-year follow-up. Indian J Gastroenterol 2009;28:206-211.

27. Rangari M, Gupta R, Jain M, Malhotra V, Sarin SK. Hepatic dysfunction in patients with extrahepatic portal venous obstruction. Liver Int 2003;23(6):434-439

28. Duche' $M$, Ducot $B$, Ackermann $O$, Gue'rin F, Jacquemin E, Bernard O. Portalhypertension in children: high-risk varices, primary prophylaxis and consequencesof bleeding. J Hepatol
2017;66(2):320-327

29. Wani ZA, Bhat RA, Bhadoria AS, Maiwall R. Extrahepatic Portal Vein Obstruction and Portal Vein Thrombosis in Special Situations: Need for a New Classification. Saudi J Gastroenterol. 2015;21(3): 129138.

30. Poddar U, Bhatnagar S, Yachha SK. Endoscopic band ligation followed by sclerotherapy: is it superior to sclerotherapy in children with extrahepatic portal venous obstruction? J Gastroenterol Hepatol 2011;26:255-259

31. Superina R, Bambini DA, Lokar J, Rigsby $C$, Whittington PF. Correction of extrahepatic portal vein thrombosis by the mesenteric to left portal vein bypass. Ann Surg 2006;243:515-521

32. Lautz TB, Keys LA, Melvin JC, Ito J, Superina RA. Advantages of the meso-Rex bypass compared with portosystemic shunts in the management of extrahepatic portal vein obstruction in children. J Am Coll Surg 2013;216(1):83-89

33. Mack CL, Zelko FA, Lokar J, Superina R, Alonso EM, Blei AT, Whitington PF. Surgically restoring portal blood flow to the liver in children with primary extrahepatic portal vein thrombosis improves fluid neurocognitive ability. Pediatrics 2006;117(3):4054012.

34. Bissonnette J, Garcia-Paga'n JC, Albillos A, Turon F, Ferreira C, Tellez L, et al. Role of the transjugular intrahepatic portosystemic shunt in the management of severe complications of portal hypertension in idiopathic noncirrhotic portal hypertension. Hepatology 2016;64(1):224-231.

35. Pargewar SS, Desai SN, Rajesh S, Singh VP, Arora A, Mukund A. Imaging and radiological interventions in extra-hepatic portal vein obstruction. World J Radiol 2016;8(6):556-570.

36. Chattopadhyay S, Govindasamy M, Singla P, Varma V, Mehta N, Kumaran V, Nundy S. Portal biliopathy in patients with noncirrhotic portal hypertension: does the type of surgery affect outcome? HPB (Oxford) 2012;14(7):441-447. 
37. Chaudhary A, Dhar P, Sarin SK, Sachdev A, Agarwal AK, Vij JC, et al. Bile duct obstruction due to portal biliopathy in extrahepatic portal hypertension: surgical management. Br J Surg. 1998;85:326329.

38. Agarwal AK, Sharma S, Singh S, Agarwal S, Girish SP. Portal biliopathy: a study of 39 surgically treated patients. HPB. 2011;13:33-39.

39. Sobhonslidsuk A, Reddy KR. Portal vein thrombosis: A concise review. Am J Gastroenterol. 2002;97:535-41.

40. Gao PJ, Zhu JY, Li GM, Leng XS. Liver transplantation for the patients with end stage liver disease and portal vein throm bosis. Beijing Da Xue Xue Bao. 2009;41:558-60.

41. Shaw BW, Jr, Iwatsuki S, Bron K, Starzl TE. Portal vein grafts in hepatic transplantation. Surg Gynecol Obstet. 1985;161:66-8.

42. Molmenti EP, Roodhouse TW, Molmenti $H$, Jaiswal K, Jung G, Marubashi S, et al. Thrombendvenectomy for organized portal vein thrombosis at the time of liver transplantation. Ann Surg. 2002;235:292-6.

43. Shaw BW, Jr, Iwatsuki S, Bron K, Starzl TE. Portal vein grafts in hepatic transplantation. Surg Gynecol Obstet. 1985;161:66-68. 